\title{
Modeling perspective for the relevant market of voice services: Mobile to Mobile
}

\author{
O. Lucía Quintero ${ }^{1}$, Fabian L. Jaramillo P. ${ }^{2}$, Manuela Bastidas ${ }^{1}$ \\ ${ }^{1}$ Mathematical Modeling Research Group, Basic Sciences Department, Universidad EAFIT, \\ Carrera $49 \mathrm{~N}^{\circ} 7$ Sur-50, Bloque 38-432, Medellín, Colombia. \\ 2 Electric, Electronic and Telecommunications Engineering Department, Universidad de Cuenca, \\ Av. 12 de Abril y Agustín Cueva, Cuenca, Ecuador.
}

Autores para correspondencia: oquinte1@eafit.edu.co,fjaramillo@ucuenca.edu.ec, mbastida@eafit.edu.co

Fecha de recepción: 15 de mayo de 2015 - Fecha de aceptación: 19 de octubre de 2015

\begin{abstract}
The markets, associated to -mobile to mobile- services of voice, in Advanced Mobile Telecommunications services in Latin America have been subject to dominant operator regulatory processes, which are necessary to attain the market conditions for optimal competition. Specifically in Ecuador, the Governmental Control Organism (Superintendence of Telecommunications) developed a model of the market to identify the convenient regulatory control actions of the Dominant Operator Regulation to achieve longterm sustainable competition in the market. The manuscript addresses the application of control systems engineering for the development of an integrated model of the market, using a neural network for the forecasting of tariffs and a neuro-fuzzy model for demand prediction. Marketing strategies for operators in this market were modeled though fuzzy inference systems and validated with real data.
\end{abstract}

Keywords: Telecommunications forecasting, state space models, neural networks, fuzzy logic, marketing, model selection.

\section{RESUMEN}

Los mercados asociados a los servicios de voz móvil a móvil, brindados por operadoras del Sistema Móvil Avanzado en Latinoamérica, han estado sujetos a procesos regulatorios motivados por la dominancia en el mercado de un operador, buscando obtener óptimas condiciones de competencia. Específicamente en Ecuador, la Superintendencia de Telecomunicaciones (Organismo Técnico de Control de Telecomunicaciones) desarrolló un modelo para identificar acciones de regulación que puedan proporcionar al mercado efectos sostenibles de competencia en el largo plazo. Este artículo trata sobre la aplicación de la ingeniería de control para desarrollar un modelo integral del mercado, empleando redes neuronales para la predicción de trarifas de cada operador y un modelo de lógica difusa para predecir la demanda. Adicionalmente, se presenta un modelo de inferencia de lógica difusa para reproducir las estrategias de mercadeo de los operadores y la influencia sobre las tarifas. Dichos modelos permitirían la toma adecuada de decisiones y fueron validados con datos reales.

Palabras clave: Pronóstico de las telecomunicaciones, modelos de espacio de estado, redes neuronales, lógica difusa, marketing, selección de modelos. 


\section{INTRODUCTION}

Ecuador's mobile telecommunications market is highly concentrated and poorly competitive, with inequalities in conditions and opportunities. The last few years, the main elements of the competitive situation in the mobile telephony in Ecuador are: network externalities, price differentiation onnet/off-net, and an important differentiation in market share with for Operator A an advantage of $43 \%$ relative to OPERATOR B, and 67\% with respect to OPERATOR C. Besides the immediate effects of inequality in market shares are: (i) the control of offer and demand by the operator with lower average tariffs as a consequence of a higher percentage of on-net traffic, and (ii) the fact that small operators in general charge a higher price, even with the same price for on-net traffic as a consequence of the higher off-net cost. The so called "group effect" favors the market advantage of the leader firm, which completely can undermine market competition (Berger, 2004a).

Currently, the Political Constitution of the Republic of Ecuador recommends equity in market conditions and opportunities. The development and permanence of competitive markets, with equity in market conditions and opportunities, are well established in the Ecuadorian law (Ecuadorian Political Constitution published in R.O. No. 449 on the $20^{\text {th }}$ of October 2008), and became a right and obligation for operators and agents in the telecommunication market. Besides, the executive act No. 1614 specifies: "The promotion of competition in specific sectors through the adoption of regulatory special actions, favoring an efficient competitive framework and removing the obstacles inhibiting free competition in telecommunications is assigned to the control authorities in the sector, despite of the jurisdiction of the Sub-Secretary of Competition."

Based on this premise and the analysis of the competitive situation on several markets in other countries in Latin America and Europe, Superintendence of Telecommunications of Ecuador SUPERTEL- decided to build a formal approach of the market using quantitative and reliable tools (mathematical or probabilisitic models that are most adopted to the nature of the problem) as to analyze the consequences of policies and regulations of several intervention scenarios. The need of a formal tool for market modeling and the posteriori calculus of the impact of regulatory interventions are based on the observation that in some countries regulatory interventions did not result in any market effect; on the contrary, in some cases affected the market negatively. Most of the regulatory interventions emerged from microeconomics (Tangeras, 2009; Yaipairoj \& Harmantzis, 2004; Hoernig, 2007; Calzada \& Valleti, 2008; Cherdron, 2001; and Hoffler, 2006), and regulatory actions were focused on the prices through modifications of access charges or establishing limits on the pricing profile. However, these approaches were inefficient in most cases and explains why the Superintendent of Telecommunications from dynamic systems perspective and control wanted to develop a model of the mobile market (Cricelli et al., 2002; Cricelli et al., 2004), using mathematical, probabilistic, econometric and/or artificial intelligence tools with the aim to understand the market's behavior, find control actions and to analyze their effects on the market.

The conceptual point of view of the control engineering perspective is analysis of the "market system" using appropriate modeling tools to understand and simulate the system, analyzing a posteriori several scenarios, and identifying the optimal control actions that minimize and/or maximize those variables that guarantee the best system performance. The highly non-linear dynamics of the real system requires the use of differential equations to adequately describe the system in terms of state variables, and establish relationships between system inputs and outputs. The way the information is propagated through the evolution of the system determines the values of states and their effects over the global output of the system (Quintero, 2009).

Mathematical representation of a real system is inexact and provides generally an approximation of the reality. The discrepancy between reality and a mathematical model is due to uncertainties in the state space model, model parameters and state variables. Consideration of the uncertainties in model predictions require the transformation of the state space model into a set of more complex equations encompassing the characteristics of the disturbances of the system to be modeled. When disturbances in the treatment of a problem are involved, it is essential to use the proper terminology and the most

\footnotetext{
1 Operator with bigger market share would have better offer (on-net and off-net).
} 
appropriate tools for its characterization, which are available in the domain of the probability theory and stochastic processes. Those disturbances can be quantified through their probability distribution function. In this way, the probability distribution of the system states determines if the propagation of information is Gaussian or not.

For the mobile telecommunications market an analysis of the system from control engineering point of view, applying mathematical tools, is conducted, encompassing respectively the development of the model and the simulation of the system. Thereafter, several scenarios are analyzed and the actions controlling the maximization or minimization of the appropriate factors that guarantee the best performance of the market derived. The research addressed a new perspective in the optimization of the policies and regulations in the mobile market, guaranteeing maximization of economics and societal benefits. The study depicts the conceptual, theoretical and empirical studies developed in Ecuador's mobile market and is as follow organized: Section 2 presents a preliminary conceptualization of the problem from the dynamic systems perspective; Section 3 provides a comparison between models and the model adopted for Ecuador's market of mobile to mobile voice services; and Section 4 illustrates and discusses model results, followed by the presentation of recommendations.

\section{PRELIMINARY FOR DYNAMIC SYSTEMS PERSPECTIVE}

A mathematical model is never an exact representation of a real system because model and systems belong to different sets, even when they are close to each other. The most obvious thing to do is to identify the model that mimics closely reality (Scaglia et al., 2002). To this end the control engineering scheme for the analysis of systems, as presented in Figure 1, was adopted. In some cases, observation of the system enables perfect measurement and understanding of the current state of the system and outputs can be expressed in terms of the states. When the states are not measurable or by lack of information of one or more variables one must rebuild the information of the system from observations (measurements) of the output and/or the states. In control systems engineering it is essential to possess full information of the system, such as the mobile telecommunications market in Ecuador, as to be able of developing and testings several applications.

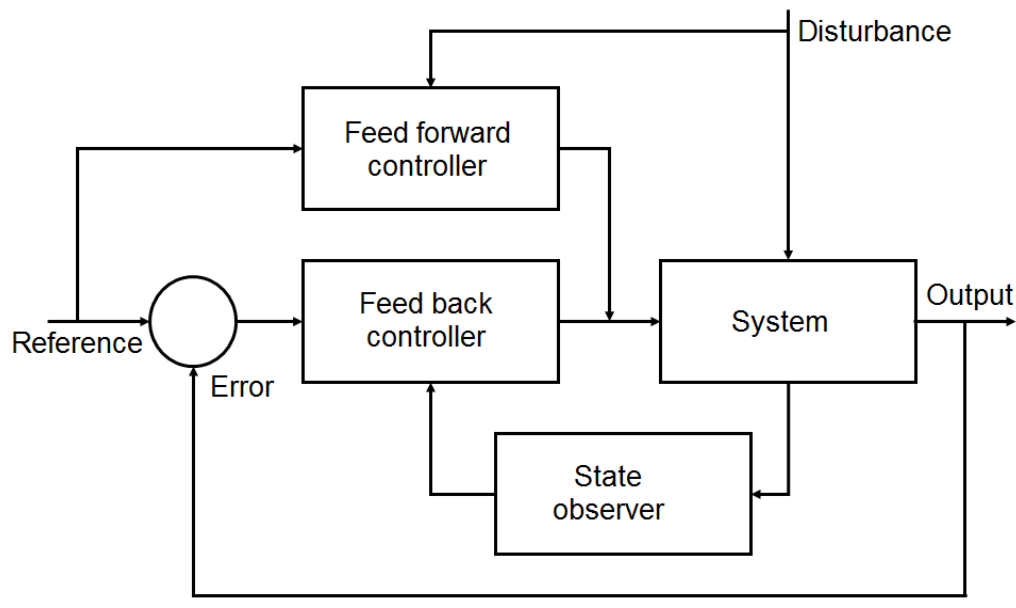

Figure 1. Control Engineering Framework for systems analysis.

Most designs of control systems are based on models representing the subtile and complex relationship between the model and the reality they represent. A mathematical model maps the relationship between inputs and outputs, and its quality depends on how close the model matches the real system and to what degree the model presentation fulfills the aim. Since no fixed and unique model exists that responds equally as the real system, one needs a set of maps. However, the problem 
of modeling is much more than that; it is the universe of mathematical models, selected from a range of models, differs from the universe of physical systems. As such, it is not possible to build a model that perfectly mimics the dynamics of the real physical system. From practical point of view, notwithstanding the degree of uncertainty of models, one should try to design a simple but good model, easy to handle, but complex enough to provide confidence to the designers that the model will work in reality (Zhou et al., 1996).

Modeling the telecommunications services in Ecuador requires a good understanding of the dynamic behavior of the system. Information about this can be derived from three distinct sources: knowledge of principles, empirical data input/output, and empiric qualitative and quantitative knowledge. Information from these sources can be combined, processed and presented in different forms, such as phenomenological models or white boxes, time series, empirical models (ARX, ARIMA, ARMAX), models based on fuzzy logic, neural networks or a combination of these. The model building process of the dynamic market system of mobile telecommunications in Ecuador involves integration of mathematical, econometric and artificial intelligence components, such as fuzzy logic and neural networks; called an adaptive neuro-fuzzy inference approach. The analysis to be performed is based on the following: i) understand its behavior, ii) to find possible control actions; and iii) analyze the effects on the market (Chiu, 1994a\&b). Econometric and mathematical tools (Berger, 2004a) are the structural basis of the model, in which economic features such as prices, demands, gains, utilities, profits, and welfares are determined by algebraic equations. Also, technical components such as the quality of services, coverage, market strategies and social items can be included through the use of other appropriate modeling techniques.

\section{MODEL OF THE RELEVANT MARKET OF VOICE MOBILE TO MOBILE}

\subsection{Comparison of modeling perspectives for telecommunication markets}

In a market scheme it is preferable to have regulatory policies which guarantee that a dominant operator does not possess a competitive advantage over the others. The telecommunications market is not an exception on this rule, and this is why the authors were looking to identify a regulatory strategy that allows the access of new operators into the market to enhance its competitive nature. It means that the regulatory agency must propose strategies that control the prices, taking care that the dominant operator not raises the off-net prices, and refrain their users not to use the competitor's networks. In the study of Berger (2004b) it is shown that from the optimal point of view, the strategy of Bill and Keep is better than the one with access prices based on costs. If the market is close to be covered, the usual network externalities are vanished but, an important type of externality remains: the network externality due to tariff mediation as described by Laffont et al. (1998a). Due to the interconnection, typical for network services, enabling the ending of calls originated in another competitor's network (Berger, 2004b), it is a common practice that the networks pay to the others access charges on a per minute basis, of which the price is negotiated among the competitors. Consequently, it is important that the model includes the dynamics of non-linear prices and the discrimination in prices based on calls termination, also named call externalities. Berger (2004b) states that the game between call externalities and discriminatory prices creates an interesting effect that can be decisive for the competition. This also applies to the case of non-linear prices. In 2004, Berger (2004b) introduced the call externalities into the standard model of network competition with price discrimination based on call termination. They continued affirming that the Bill and Keep strategy can improve the total benefit compared to the strategy of access prices based on costs.

These models predict that under a linear price rule the negotiation of access charges is used as a negative tool. Subsequently, it has been shown that access prices below the marginal cost can be the result of the competition, for example in cases when networks compete in a scheme of "two-part" tariffs with discriminatory prices; it is when the function of demand for subscription is elastic, or in case when the ex-ante investments are inadequate. On the other hand, an analysis about the regulatory intervention is appropriate for the cases the tariff of network externalities are mediated (Hoernig, 2007). Analyzed scenarios are: i) high prices in off-net calls and on-net calls below the efficient level 
(under the cost); and ii) the smaller operator can leave the market, reinforcing the profits of the bigger operator.

Possible solutions to solve previous mentioned intervention scenarios are: to reduce the calls termination charges for both networks, to reduce the termination charges of the bigger network, to introduce limits over the on-net/off-net differentials, or to introduce limits on the off-net margins. The model includes the on-net costs, access charges (fixed by regulator), off-net costs, additional utility, network asymmetry, direct and indirect utility, calls duration, demand function and utility. Benefits, profits, consumer surplus and total welfare are considered similar to the Berger model. The choice for maximization of the benefits of the discrimination between variable and uniform prices depends on the demand and exact cost features, which normally are moderately known in industry regulations. Any intervention has the risk to diminish the benefit instead of increasing it.

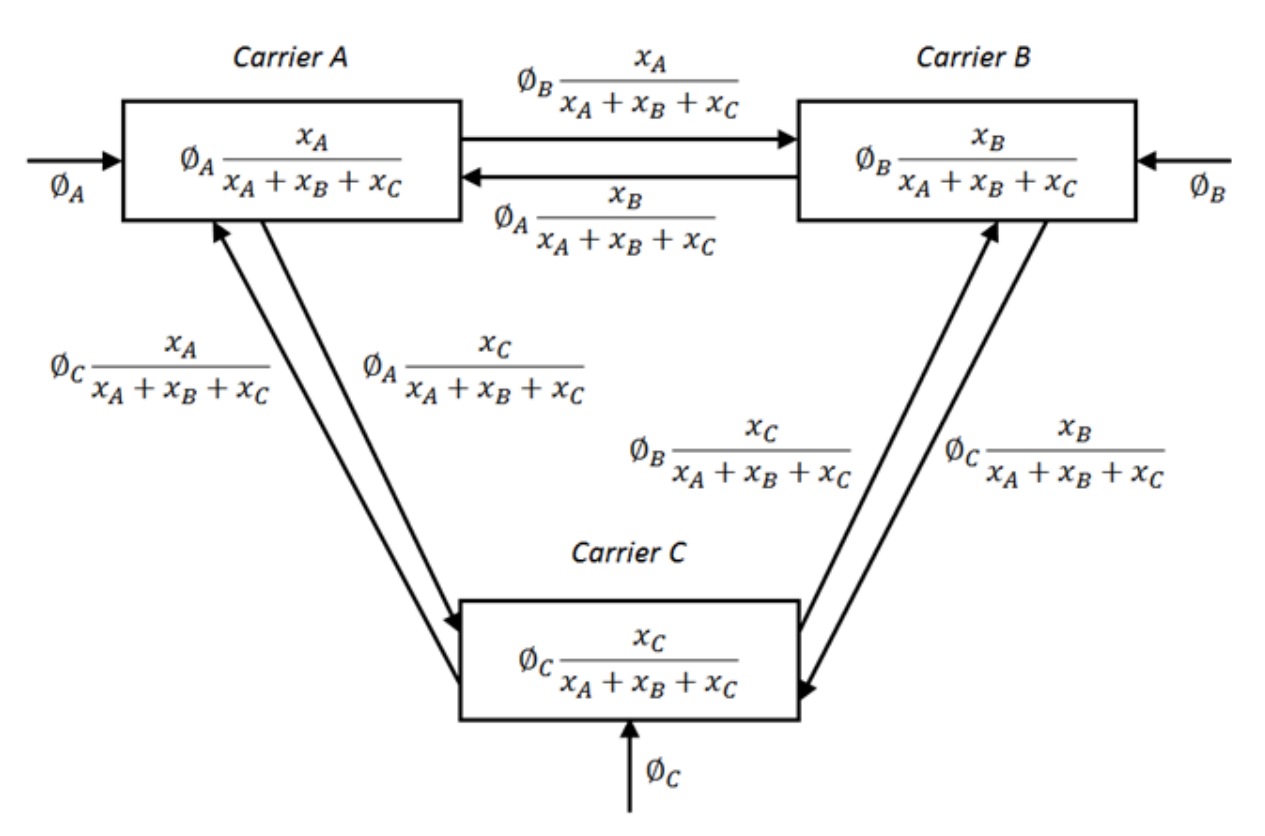

Figure 2. Analysis scheme for competition in the Italian mobile telecommunications market.

Cricelli et al. (2002), for studying the impact of the competition in the Italian telecommunication mobile market, used in their study the competition scheme shown in Figure 2. The objective of their work was to analyze the impact of a growing competitive pressure due to the entrance of a new operator. With this aim, the model analyzes the entrance of the competitor "C" into the market composed by two competitors: an operator " $\mathrm{A}$ " and a consolidated operator "B". Those authors considered the market as a dynamic system using the so called control engineering term states spaces, and they defined the market as follows:

$$
\begin{aligned}
& \dot{x}_{A}(t)=k_{A A}\left(X(t)-x_{A}(t)-x_{B}(t)-x_{C}(t)\right) \\
& \dot{x}_{B}(t)=k_{B B}\left(X(t)-x_{A}(t)-x_{B}(t)-x_{C}(t)\right) \\
& \dot{x}_{C}(t)=k_{C C}\left(X(t)-x_{A}(t)-x_{B}(t)-x_{C}(t)\right)
\end{aligned}
$$

where the state variables $x_{A}, x_{B}, x_{C}$ are the ratio of users in each operator; $\mathrm{X}(\mathrm{t})$ the total users growth; $p_{A}, p_{B}, p_{C}$ the prices of the operators; and the coefficients $\mathrm{k}_{\mathrm{ij}}, \mathrm{i}, \mathrm{j}: 1,2,3$ feature the market behavior. These state variables depict the relationship between the demand functions and the flux of traffic calls. The model assigns a distribution of the flux of traffic as a function of the gain functions that includes the components gains for originating and receiving calls into the network, and the call reception costs, incomes for interconnection costs, and a fixed cost. In fact each network operator chooses at the end a price based on the interconnection level and an interconnection tariff fixed by a regulator. The most interesting point in the work of Cricelli et al. (2002) is the selected state variables 
perspective, because it permits to establish a differential equation system for the number of subscribers in each operator, and as control variable the price strategy that maximizes each period of time the cumulative profits in an infinite horizon. This approach led us to the control engineering perspective of chosing an objective function (cumulative profits) of all the operator's profits, taking into account a decreasing monthly cost of marketing and an exponential growth of the market. In this way, optimal prices are approximated in the sense of a functional cost, setting a hit to complete a model that includes price discrimination strategies for interconnected networks (Cricelli et al., 2004). Basically, it highlights the results of a strategy of price discrimination in terms of market shares and profits, with the aim to identify the obligatory behaviors which can inhibit the competition in that market.

With respect to the different cases and scenarios of the markets and the different kinds of models being used, it is interesting to mention the work of Tangeras (2009), who checked the neutrality of the profits from the access charges into a network competition. This author demonstrated that, depending on a specific property of the subscription demand, the neutrality of access charge profits in case of the network's profits is independent from the access charges of the "two-part" tariff of calls. The latter suggests the need to include a demand model into the general analysis. Yaipairoj \& Harmantizis (2004) proposes a possible technical solution to some of the mentioned problems of call prices, access charges or tariffs variations. Solutions to these are in telecommunication networks traditionally pursued by the introduction of dynamic price schemes, incentivizing the users, and improving the use of the network resulting in a maximization of the profits. It might look evident that the implementation of this type of scheme in data or internet networks is easy to accomplish, but as a consequence of congestion scenarios and the service quality of some operators in Ecuador's mobile telecommunications market, it is worth mentioning the conclusions of Yaipairoj \& Harmantizis' work: "As a consequence of the dynamic price scheme in priority telephony systems, two alternatives are presented to the users: a dynamic price scheme when a superior amount of service is delivered, or a lower price is fixed degrading the performance of the service"; the latter being subscribed by Armstrong \& Sappington, 2007; Cabral, 2011; Asgari et al., 2013; Stanikūnas \& Burinskas, 2011; Sepúlveda Botero, 2013; Cricelli et al., 2011; Peres \& Hilbert, 2009; Brousseau \& Glachant, 2002; among other authors.

\subsection{Methodology for modeling Ecuador's mobile to mobile voice market}

A basic functional model is presented for the specific problem, encompassing techniques such as stochastic modeling, fuzzy logic, neural networks, and adaptive neuro-fuzzy inference tools, used complementary to the economic model, and including specific dynamics detected into the qualitative and quantitative analysis of the market. Due to the variation and the lack of information in tariffs of the year 2008, it was necessary to preprocess the data, to define the missing ones, evaluate the tendencies and to verify the correlation among the data. Linear tendencies were used to complete the missing data, and a stochastic process was added to the completed data to simulate the variation of the prices. A model based on neural networks to evaluate the tendencies of prices was built, with the aim to analyze the price dynamics set by the operator into the market. This means, to verify the tendency of the operators B and C to modify tariffs in function of the regulatory actions taken by operator A.

A fuzzy logic model was developed to evaluate the effect of the market strategies, user's socioeconomic classification for tariff variation (sales) and group effect over traffic and users growth (Mamdani, 1974). Due to the non-linearity of the demand of calls (traffic on-net and off-net), it was necessary to use an adaptive neuro-fuzzy inference system, the so-called ANFIS tool, to model the several traffic profiles to the three different operators into the market as a function of the on-net and off-net prices (Jhyshing \& Chuen-Tsay, 1993; Buragohain \& Mahanta, 2008). Posteriori, the mathematical model, including the externality of calls and network (Armstrong \& Sappington, 2005) and their effects over the utilities and demand elasticity in the market, is completed. The structure of the model is presented in Figure 3 (Bastidas et al., 2013). 


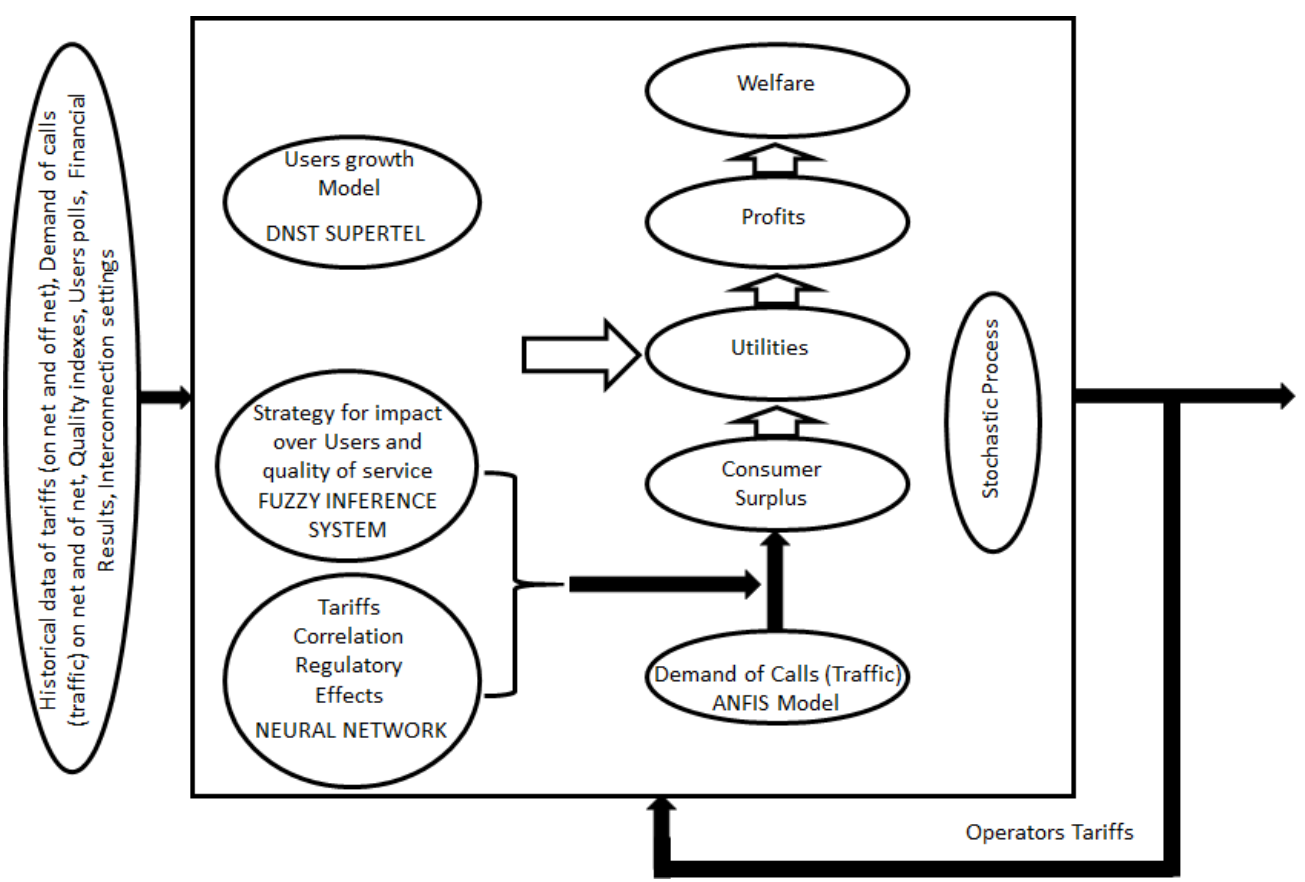

Figure 3. Model scheme for Ecuadorian mobile telecommunications market.

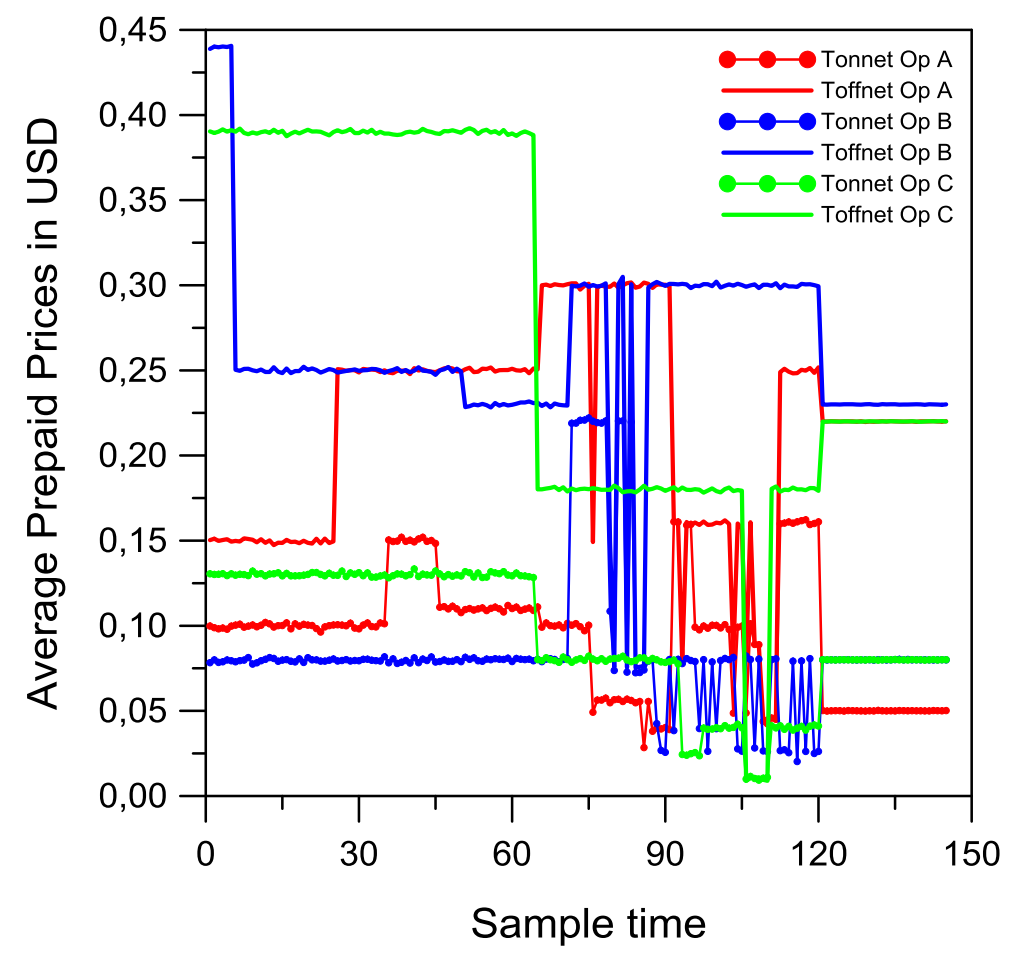

Figure 4. Average Prepaid Prices scenarios of Ecuador's mobile telecommunications market.

\section{Data pre-processing}

Tariff data was collected from operators' reports to the regulatory agencies and the Superintendence of Telecommunications, for the period 2008-2010. The provided data offers information of prepaid and post paid segments, in on-net and off-net call profiles. In 2008 missing data due to shortcomings in the operator's reports were reconstructed using a linear model for each competitor, and an analysis of the data was conducted to extract the stochastic features of the time series. That year, tariffs did not present big changes and variations were more frequent in the postpaid segment because of the 
increase in the offer to corporate clients in cheaper plans as a strategy for gain users. After data completion, including the characterization of the stochastic features and tendencies, experts of the Superintendence validated the datasets. The readers' attention is drawn to the fact that given several plans were offered to the users in the prepaid and postpaid segments, prices were averaged in proportion to the number of users' in each category. The Figures 4 and 5 show the average prices in prepaid and postpaid segments of the three operators not only in the on-net but also on the off-net calls.

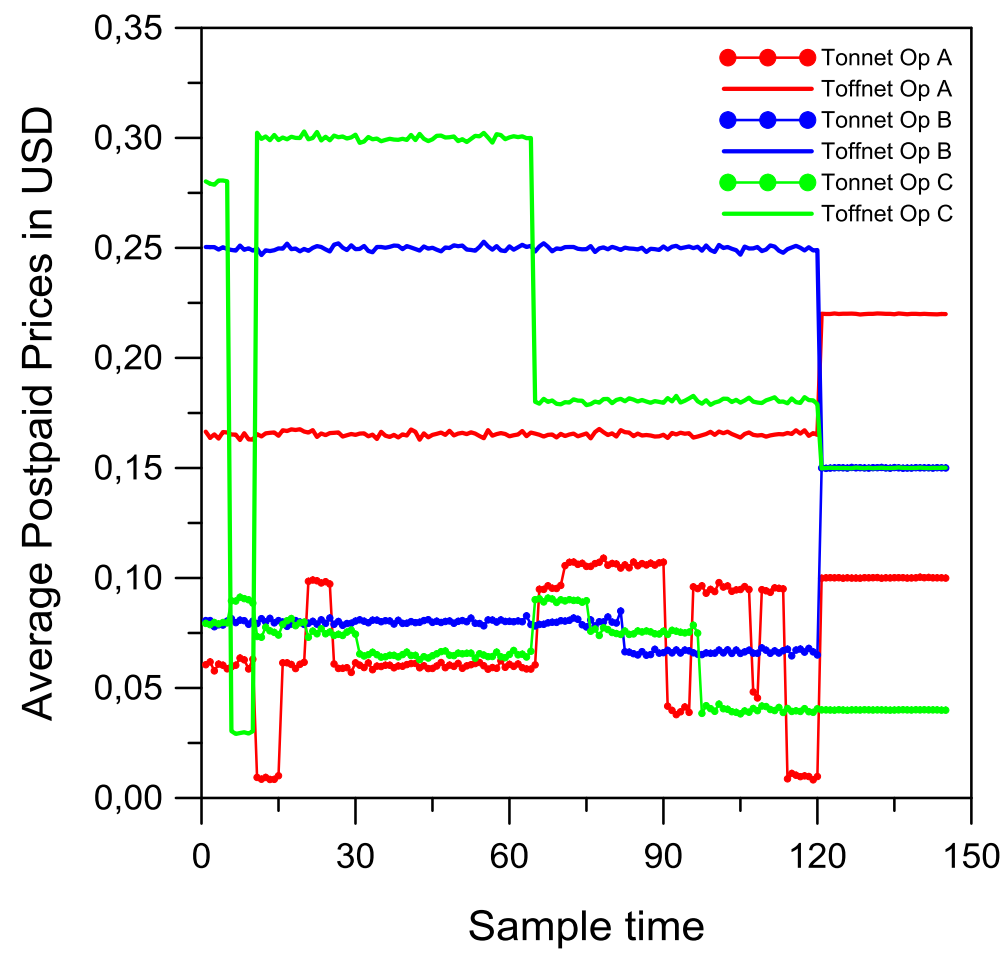

Figure 5. Average Postpaid Prices scenario of Ecuador's mobile telecommunications market.

Several analyses of the reports of the operators to the regulatory agencies revealed that the sample time for this market is 5 days. External dynamics were reflected by data, such as in 2009 an operator reported several changes in tariffs due to the entrance of new marketing strategies such as sales $(2 \times 1,3 \times 1,5 \times 1$ minutes), and another operator reported an increasing in the frequency of promotions in specific regions of the country through special and sponsored events in places of urban population concentration such as big shopping centers. The Figures 4 and 5 clearly show the effect of those interventions on the system dynamics in sample times 110-130. Also, both figures depict the effect of the regulatory policy introduced by the entrance of portability in the last trimester of 2009 . The average of the off-net prices diminished previous the regulatory measurement, but after a month of the portability entrance, prices raised again to previous values. In December 2009 and the beginning of 2010, operators fixed tariffs and demonstrated a competitive strategy not related to prices.

\section{Neural network relationship model}

The approach to model the advanced mobile system using artificial neural networks is presented in the following. The objectives of developing a neural network model were to verify and check the overall interpolation capacity following possible extrapolation trends. Initially, the use of a neural network to estimate the influence of technical factors in the structural model was proposed, but finally we choose to make a direct check about the information on tariff data to identify possible characteristic features in the change of the rates on data of prepaid and postpaid segments. For this purpose three types of neural networks were built: a) Network 1 trained with all prepaid data to estimate each of the pairs 
(Ton-Toff $\mathrm{MTM}^{2}$ ) rate of the operators; b) Network 2 couple of estimates of rates (Ton-Toff MTM) of an operator with prepaid data of the two remaining operators; and c) Network 3 stochastic component added to the prepaid data, estimation of two pair of prices (Ton-Toff MTM) of an operator with prepaid data of the two remaining operators.

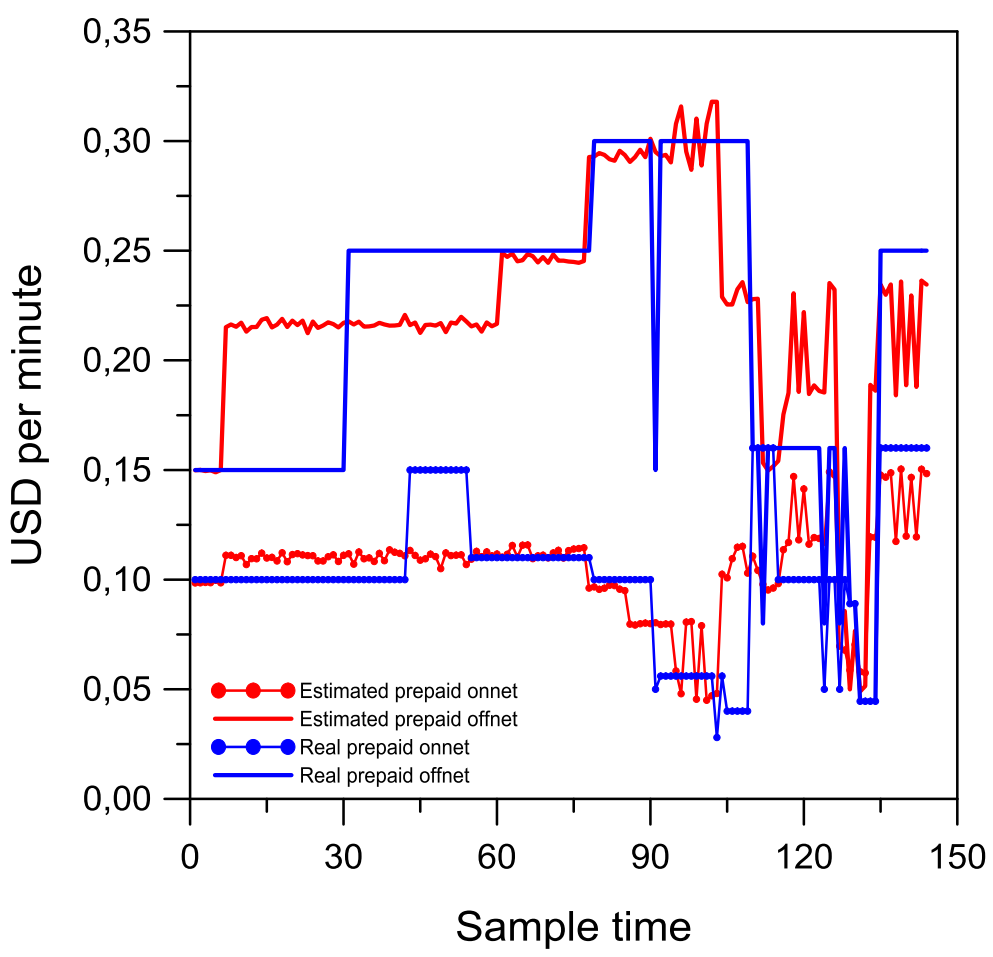

Figure 6. Neural Network estimation of tariffs for Operator A.

The neural networks are used to estimate pair of rates (Ton-Toff MTM) of an operator with prepaid data of the two remaining operators. Figure 6 shows the results for the estimation of rates of operator A, and illustrates that the neural network follows the trends of data rates for operator A. However, it is important to notice that the chart reveals a delay in the main estimate, indicating a causal relationship between the pair rates and those that are the input to the network for their estimation, confirming the hypothesis (Hurtado et al., 2014).

Figure 7 shows the results of the neural network trained to estimate the prices of operator B, depending on the prices of the other operators in the prepaid segment. From this figure it can be seen that the network follows the trends in prices, but fails to correctly model the actual data. The dotted lines depict the estimates of the net, and the solid lines the real data. Figure 8 shows the results of estimating the rates of carrier C, using previously described type III network and as input the prepayment rates of the operators $\mathrm{A}$ and $\mathrm{B}$. The figure highlights the importance of this stage of model development, the fact that they check the properties of the artificial intelligence tool and this confirmed their presence for the estimation of parameters within the mathematical model to reflect other socio-economic impacts on operator rates.

\footnotetext{
${ }^{2}$ Ton-Toff MTM: Tariff on-net, Tariff off-net, MTM = Mobile to Mobile.
} 


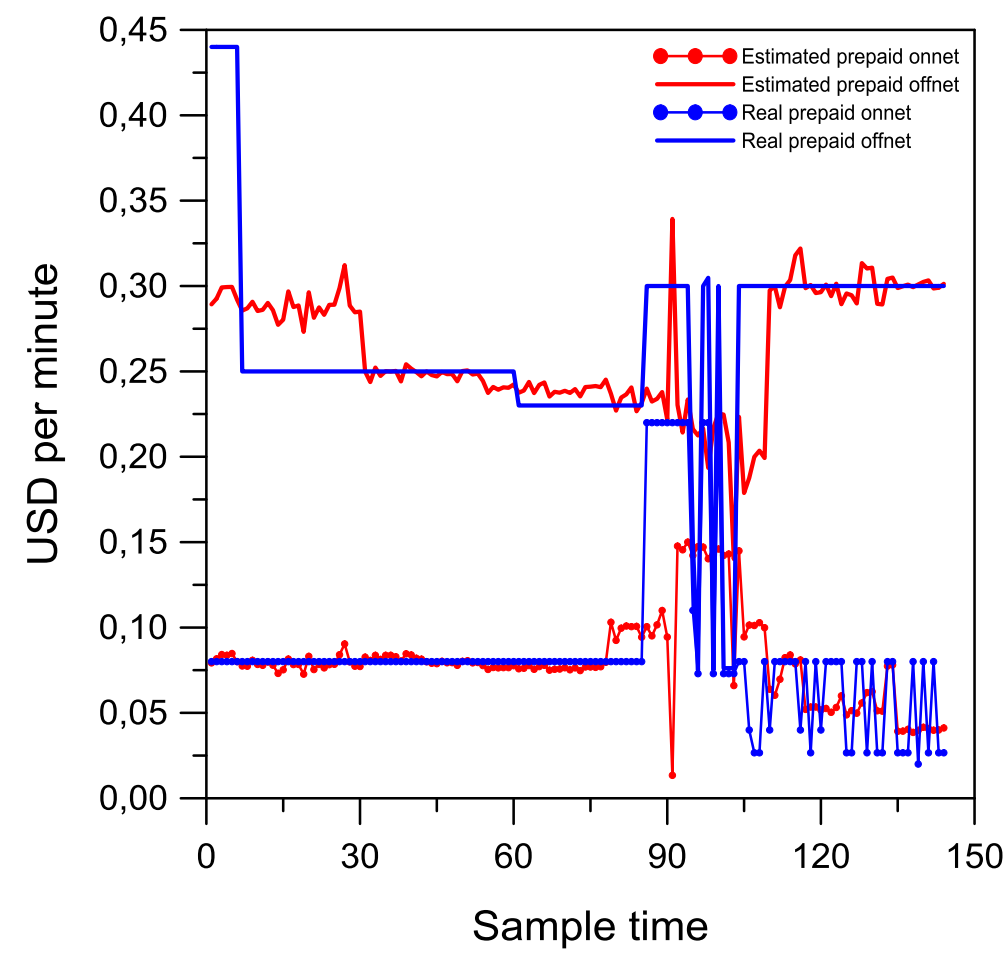

Figure 7. Neural Network estimation of tariffs for Operator B.

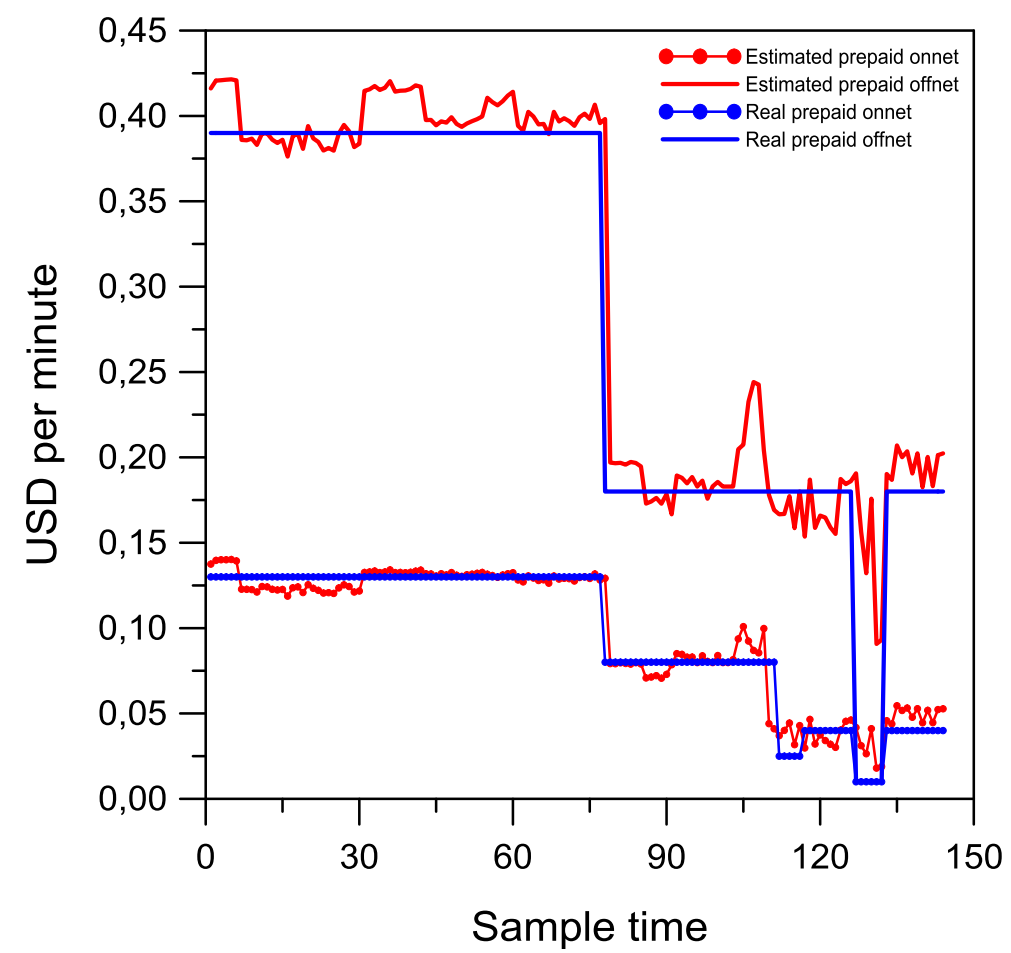

Figure 8. Neural Network estimation of tariffs for Operator C.

The ANFIS demand model

A complete demand model of the market, being the main objective of this work, was developed because the interactions between prices and demand of calls (volume of calls - traffic) on- and off-net are not met by the traditional models of demand found in the literature (Cricelli et al., 2002 and 2004; Tangeras, 2009; Yaipairoj \& Harmantzis, 2004; Hoernig, 2007; Calzada \& Valleti, 2007; Chedron, 2002; Laffont et al., 1998b; Berger, 2004b; and Hoffler, 2006). From econometric point of view 
interactions exist between the prices and the demand, and between the demand and the consumer surplus.

A hybrid model, in which a combination of fuzzy antecedents and consequents are calculated from a neural network, is proposed. In this hybrid model, called ANFIS (Jhyshing \& Chuen-Tsay, 1994), are the demand of calls (traffic) on-net and off-net estimated from the data prices of the operators in Ecuador's telecommunications market. The model is composed by the following inputs and outputs: Inputs: a. Price on-net prepaid, b. Price off-net prepaid, c. Price on-net postpaid, d. Price off-net postpaid Mobile to fixed operator, e. Price postpaid Mobile to Mobile; Outputs: a. Traffic onnet, $b$. Traffic off-net. The data of traffic (minutes of calls) into the mobile networks in Ecuador is collected for three different items: Incoming Traffic, Outgoing Traffic and On-net Traffic. Figure 9 shows for the three operators the real (Fig. 9a) and estimated (Fig. 9b) demand of on-net and off-net calls in prepaid and postpaid segments. These results feed the consumer surplus model, obtained by numerical integration of the results. Theory indicates that the consumer surplus rate is proportional to the negative of the demand function, and also the utility function is proportional to the traffic on-net, off-net and other variables.

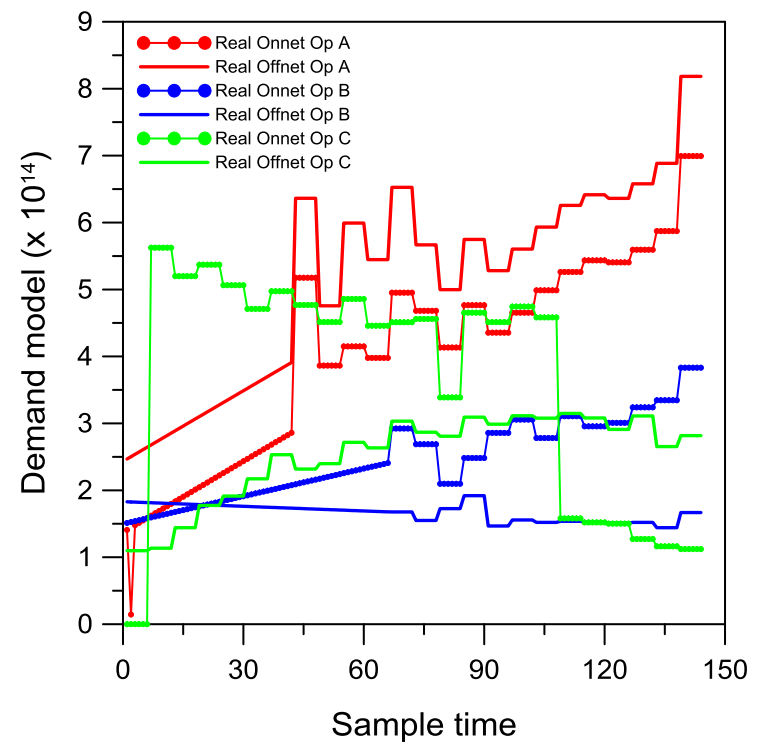

(a)

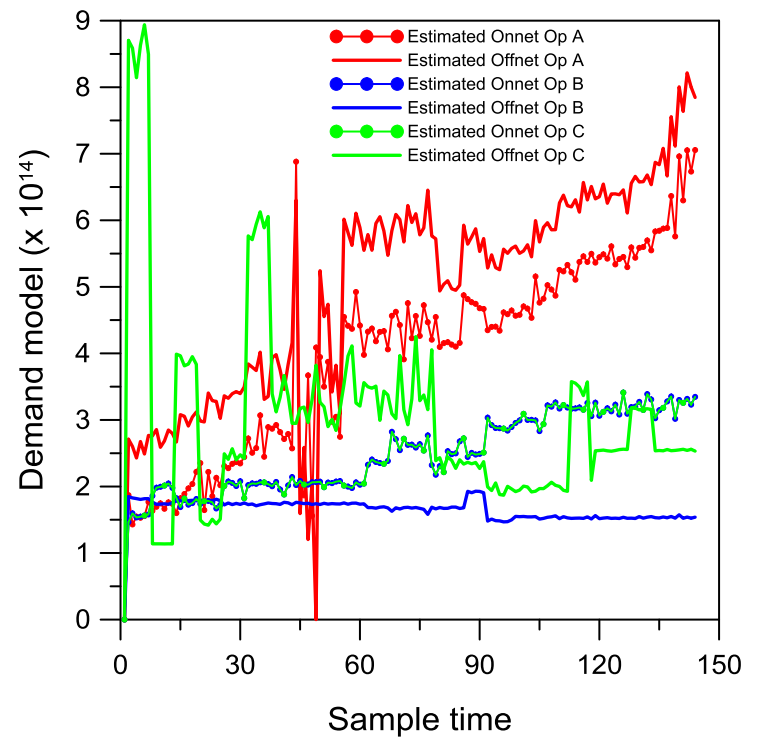

(b)

Figure 9. Real (a) and estimated (b) demand of calls (Traffic) on-net and off-net for operators in Ecuador's Mobile Telecommunications Market.

\section{Regulatory actions}

The best market case is the one in which on-net and off-net prices are equal and are below cost, because they internalize the externality of the call. The price discrimination between calls is inefficient, and benefits increase when prices fall to efficient levels. The analysis of the market equilibrium is performed through the Nash equilibrium, in the case of constant market share. On-net prices internalize the utility of subscribers to receive calls leading to efficient prices below marginal cost. Off-net prices remain below marginal cost and increase market share. In symmetric equilibrium, consumer surplus is determined by the degree of market competitiveness.

The above described scenario is in no way satisfied in the Ecuadorian market, and it is said in the regulation that price should not be below cost (not to engage in unfair competition). Consequently, the developed model predicts scenarios that do not correspond to the Nash equilibrium scenario. For this reason and after making appropriate dynamic analyses, based on the development and analysis of the completed model, it is realized that the optimal control actions on the market are not yet realized in Ecuador. Ecuador still enforces the rules of the call termination charges or the negotiated interconnection charges between operators, either mobile to mobile or mobile to fixed or vice versa. 
This led operators to take control of their rates, thereby stimulating the generation of the phenomena of market distortion. To date, regulatory decisions have been "set tariff ceilings" and "taking control with respect of them", but the variable interest can influence much more strongly the market. In this work several theoretical and practical developments, defining the state of the art on the topic, were analyzed, similar to Hoernig's work (2007) in which regulatory interventions were evaluated using a similar model as used in this project. Additionally, this research included evaluation of the simulation results generated by the developed model, and the definition of the "control actions" (or manipulable variables), which from the control engineering approach have direct influence. These are the interconnection charge and the differential of prices of Ton/Toff-net. The latter must be set appropriately, according to criteria aiming maximization of consumer surplus and total profit.

\section{Fuzzy model for marketing strategies}

The model-based approach was performed with the purpose to associate the perception of the users to their Mobile Phone Operator choices and consequently the creation of the so-called group effect, network externalities and call externalities. To build the model, an evaluation of the main features in strategic marketing was performed and from this perspective, four main variables were identified and used as inputs to the model. The fuzzy model was built in Matlab ${ }^{\circledR}$ and the variables selected as inputs to the linguistic relational model were: a) low prices strategy, b) unique experience of consumer, c) product quality and d) focuses on a market niche. The purpose was to try to diagnose what the influence of the selected inputs is over the choices of the user about to make or not calls on-net, offnet, and specifically if the user will choose again its mobile phone operator, evaluating the possibility of the growth of the carrier due to that reasons. In this way, the mentioned inputs feeded to the Fuzzy Inference System generated the following outputs: a) on-net traffic, b) off-net traffic, and c) number of user's growth.

About the "low prices strategy" the user's perception over the operator tariffs was evaluated, and the domain for that variable was initially defined with three membership functions: very, medium and not used low price strategy. It refers precisely to the situation whereby the operator can use this strategy to reduce the tariffs, or not use it through the introduction of non competitive prices. Respect to the second input, the "unique experience of consumer", it is important to evaluate the fact if a user is identified to the brand of the operator, considering it as a life style with focus on the operator's abilities of communication with friends or a specific group. The domain was divided in three membership groups such as bad, good and excellent. Likeways, the input "product quality" is evaluated with the membership groups: bad, good and excellent, making it easy for the user to qualify his perception of the operator's service. Finally, the input "focus on the market niche" is orientated to the fact that user's feel or perceive that the operator attends his specific needs. This model was designed to reflect the strategy of the Operator A, locating the promotions or decreasing over the onnet prices specifically in certain sectors of the country, stratified under the concept of events, city neighborhoods and specific needs of corporative groups. The same model was developed for the operators B and C. Figure 10 shows an example of the surface generated by the model of Operator C, estimating the off-net traffic variable from the inputs "product quality" and "low cost strategy".

As can be seen in Figure 10, Operator $\mathrm{C}$ is strongly subject to the call externality of the other operators, while operator B exhibits a high sensitivity of off-net traffic to a decline in service quality. Regarding to the network externality, operator $\mathrm{C}$ shows a growing trend of users in case the consumer experience is more positively rated. In short, changing the market share of an operator not only works out by a change in the prices of carriers, which results in a tendency towards the internalization of call externalities, but also depends from the efforts of the operators B and C to increase their market share, respectively by focusing on product quality and/or changing market niches. The latter happens in response to the perceived competitive weaknesses of the users and the network externality, suggesting an evaluation and a detailed study of the competitive strategies of the operators. Hence, to make an assessment of the market distribution after regulatory interventions requires combination of the mathematical model that evaluates the effects of price on earnings, and the fuzzy model assessing the sensitivity on the growth of on-net and off-net user traffic, in addition to an economic evaluation. 


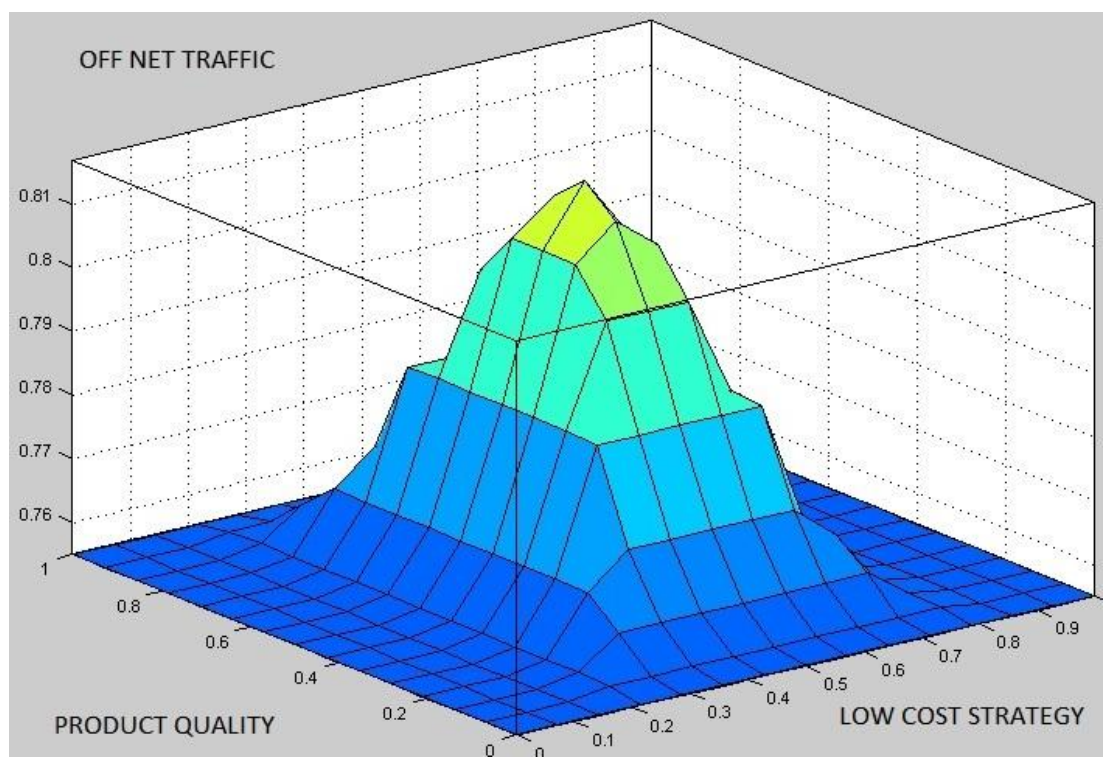

Figure 10. Surface generated in the fuzzy model for Operator $\mathrm{C}$ in relationships of marketing variables over traffic (demand of calls).

\section{CONCLUDING REMARKS AND RECOMMENDATIONS}

First, we found that the number of mobile operators can reduce network effects by reducing the termination fee to the monopoly level, restimulating the bottleneck problem of competition. Second, if a network has a larger subscriber base than the others, then you may prefer to strengthen the network effects rather than weakening them, making it more difficult for other operators to compete in this area. The key to this (without relying on the threat of regulation) would relax the fixed operator's obligation to interconnect with any mobile phone operator, leaving the position of mobile call termination. Consequently, mobile networks could compete for the right to deliver the $\mathrm{MTF}^{3}$ call fixed-line operator, resulting in lower mobile termination rates.

Examination of the interaction of three mobile operators and a fixed carrier resulted to the establishment of the following regulatory measures:

a. To set interconnection charges between mobile operators; and

b. To set limits on the asymmetric tariff differential (the differential is measured as the division between the price on-net and off-net price) above 0.4 and below 0.75 , and eventually assign a flat rate. This might be unpopular, and therefore it is recommended to evaluate a priori the side effects by the respective authorities.

Those measures enable the regulator to:

a. Set a price range among the operators offering services of voice traffic; in this way prices will be between the floor and the roof;

b. Ensure that the rates are above the costs estimated by the regulator; and

c. Assuming that the on-net prices of operators remain on the tariff floors, with a degree of uncertainty around the current values, assign a limit to the price differential that encourages a reduction of the off-net prices (or a slight increase in the on-net price) as to keep the differential. The latter will help to close the gap that currently exists between the on-net and off-net rates of operators, and stimulate the generation of non-differentiated rates, changing traffic patterns accompanied by an encouragement in the transfer of profits.

\footnotetext{
3 MTF: Mobile to Fixed
} 
Having control over the values of the off-net rates (calculated as the price differential divided by the on-net interconnection charges) and imposing a differential greater than 0.4 based on actual rates, the operators will never reach the current roof values. There is presently a ceiling rate, which allows control over the maximum value of $\mathrm{SMA}^{4}$ carriers charging user calls, and there are no disadvantages around it compared to the rates reported by the operators. However, when operators report very low rates there is a flat rate that allows controlling the truthfulness of a rate case since the operator updates the promotional rate, turning it finally into a permanent rate.

\section{REFERENCES}

Armstrong, M., D.E.M. Sappington, 2005. Recent developments in the theory of regulation. Available at http://www.econ.ucl.ac.uk/downloads/armstrong/reg.pdf, 137 pp.

Armstrong, M., D.E.M. Sappington, 2007. Recent developments in the theory of regulation. In: Handbook of Industrial Organization. Handbooks in Economics, 3(10), 1557-1700. Elsevier (North-Holland).

Asgari, N., R.Z. Farahani, M. Goh, 2013. Network design approach for hub port-shipping companies' competition and cooperation. Transp. Res. Part A: Policy Pract., 48, 1-18.

Bastidas, M., O.L. Quintero, J. Garcia, 2013. Inteligencia de mercados: Comportamientos estratégicos sobre precios de oferta en el mercado Spot Eléctrico Colombiano (Market intelligence: Strategic behaviors with prices in the Colombian Electricity Spot). Universidad EAFIT, Centro de Investigaciones Económicas y Financieras, Documento de Trabajo Economía y Finanzas, No. 13-06, 22 pp. Available at https://repository.eafit.edu.co/bitstream/handle/ 10784/679/2013_6_Jhon_Jairo_Garcia.pdf?sequence=1.

Berger, U., 2004a. Bill and keep vs cost-based access pricing. J. Econ. Lit., L41, L96, 10 pp.

Berger, U., 2004b. Access charges: the presence of call externalities. J. Econ. Lit., L41, L96, 19 pp.

Brousseau, E., J.M. Glachant (Eds.), 2002. The economics of contracts: Theories and applications. Cambridge University Press, $604 \mathrm{pp}$.

Buragohain, M., C. Mahanta, 2008. A novel approach for ANFIS modelling based on full factorial design. Appl. Soft Comput., 8(1), 609-625.

Cabral, L., 2011. Dynamic price competition with network effects. Rev. Econ. Stud. 78(1), 83-111.

Calzada, J., T. Valletti, 2008. Network competition and entry deterrence. Econ. J., 118(531), 12231244.

Cherdron, M., 2001. Interconnection, termination based price discrimination, and network competition in a mature telecommunications market. Economics Department, Universität Mannheim, 46 pp. Available at http://www.vwl.uni-mannheim.de/gk/wp/gkwp-2000-03.pdf.

Chiu, S. 1994a. Fuzzy model identification based on cluster estimation. J. Intell. Fuzzy Syst., 2(3), 267-278.

Chiu, S. 1994b. Selecting input variables for fuzzy models. J. Intell. Fuzzy Syst., 4(4), 243-256.

Cricelli, L., M. Gastaldi, N. Levialdi, 2002. The impact of competition in the Italian mobile telecommunications market. Netw. Spat. Econ., 2, 239-253.

Cricelli, L., F.D. Pillo, N. Levialdi, M. Gastaldi, 2004. Mobile telephony industry: Price discrimination strategies for interconnected networks. In: Proceedings of ICT, 2004, 192-198.

Cricelli, L., M. Grimaldi, N.L. Ghiron, 2011. The competition among mobile network operators in the telecommunication supply chain. Int. J. Prod. Econ., 131(1), 22-29.

Hurtado, L., O.L. Quintero, J.J. García, 2014. Estimación del precio de oferta dela energía eléctrica en Colombia mediante inteligencia artificial. Revista de Métodos Cuantitativos para la Economía y la Empresa, 18, 54-87. Available at http://www.upo.es/RevMetCuant/pdf/vol18/art96.pdf.

4 SMA: Advanced Mobile System 
Hoernig, S.H., 2007. On-net and off-net pricing on asymmetric telecommunications networks. Inf. Econ. Policy, 19(2), 171-188.

Hoffler, R. 2006. Monopoly prices versus Ramsey-Boiteux prices: Are they 'Similar', and: Does it Matter? JICT, 6(1), 27-43.

Jhyshing R. J., S. Chuen-Tsay, 1993. ANFIS: adaptive-network-based inference system. IEEE Trans. Syst. Man. Cybern., 23(3), 665-685.

Laffont, J-J., P. Rey, J. Tirole, 1998a. Network competition: I. Overview and nondiscriminatory pricing. RAND J. Econ., 29, 1-37.

Laffont, J-J., P. Rey, J. Tirole, 1998b. Network competition: II. Discriminatory pricing. RAND J. Econ., 29, 38-56.

Mamdani, E.H., 1974. Application of fuzzy algorithms for the control of a dynamic plant. Proc. IEEE, 121(12), 1585-1588.

Peres, W., M.R. Hilbert (Eds.), 2009. La Sociedad de la Información en América Latina y el Caribe: Desarrollo de las Tecnologías y Tecnologías para el Desarrollo. Libros de la CEPAL, 381 pp.

Quintero, O. L., 2009. Particle filters for non linear non gaussian systems: state estimation and applications. PhD. Thesis. Temas de Automática, Universidad Nacional de San Juan, Argentina. ISBN: 978-987-05-8642-5.

Scaglia, G.J.E., V.A. Mut, J.F. Postigo, B. Kuchen, 2002. Control de robots móviles aplicando técnicas de control robusto. En: Aplicaciones de Control Robusto en Robótica. Editado por Red Iberoamericana de Informática Industrial (RIII), 23 pp. Available at http://www.inaut.unsj.edu.ar/ Files/Sc1414_02.pdf.

Sepúlveda Botero, B.B., 2013. Aproximación al modelo del mercado de telecomunicaciones móviles en Colombia desde la perspectiva de control. Tesis de Grado, Universidad EAFIT, Medellín, Colombia.

Stanikūnas, R., A. Burinskas, 2011. The analysis of competition in cellular mobile telephone markets. Economy\&Management, 16, 366-372.

Tangeras, T., 2009. On the profit neutrality of access charges in network competition. Research Institute of Industrial Economics, Stockholm, Sweden, 9 pp. Available at http://www.konkurrensverket.se/globalassets/forskning/projekt/on-the-profit-neutrality-ofaccess-charges-in-network-competition.pdf.

Yaipairoj, S., F. Harmantzis, 2004. Priority telephony system with pricing alternatives.

Telecommunications and Networking - ICT 2004. Lecture Notes in Computer Science, Vol. 3124, 183-191. Available at http://link.springer.com/chapter/10.1007\%2F978-3-540-278245_26.

Zhou, K., J.C. Doyle, K. Glover, 1996. Robust and optimal control. Prentice Hall, Englewood Cliffs, New Jersey, 603 pp. Available at http://ir.nmu.org.ua/bitstream/handle/ 123456789/121597/abce392a817af84ec3ffa869fcd21db2.pdf?sequence=1. 